\title{
Computational Accuracy of Radiation Emerging from the Ocean Surface in the Model Atmosphere-Ocean System
}

\author{
by \\ Kazuhiko Masuda and Tsutomu Takashima \\ Meteorological Research Institute Tsukuba, Ibaraki 305, Japan
}

(Received Nov. 11, 1985 ; Revised Jan. 14, 1986)

\begin{abstract}
Computational accuracy of the Cox-Munk ocean surface model is discussed using the energy conservation of the incident radiation on it. The computational scheme in the atmosphere-ocean system is based on the doubling-adding method. Firstly.. with the aid of the simple modification of the refraction matrix, computational accuracy is significantly improved even in the small discrete system of $(15,24)$, where the first and second numerals in the parentheses donote the discrete coordinates in the atmosphere and the ocean, respectively. This modification is necessary especially for the computations of the radiation including polarization effect which require a great deal of computer time and memory space. Secondly, the effects of shadows, multiple reflections, and refractions by the ocean surface are discussed to improve the accuracy. Finally, a computational example of albedo, the upwelling radiance and the degree of linear polarization at the top of the atmosphere-ocean system are discussed at wavelength $0.5 \mu \mathrm{m}$.
\end{abstract}

\section{Introduction}

Computer simulation of radiative transfer in the atmosphere-ocean system is useful not only for the interpretation of the remote sensing data observed by satellites, airplanes and ships, but also for the developement of remotesensing techniques. Upon computing the radiation in the visible or its adjacent wavelength regions, the reflection and the refraction by the ocean surface should appropriately be treated, together with the scattering and the absorption in the atmosphere and the ocean. Here the computational accuracy of the radiation reflected or transmitted by the atmosphere can separately be investigated using the energy conservation law for a pure scattering medium. It was found that a computational accuracy would be satisfactory in a rather small system of 15 discrete quadrature points.

As for the ocean surface, the radiation refracted by the surface tends to become large at the direction connected by Snell's law. Thus to simulate the refracted radiation accurately, large discrete coordinates would required. Previously a system of $(15,24,45)$ was adopted by Takashima and Masuda (1985) in their model computations, where the numerals in the parentheses represent the discrete directions in the atmosphere, in the ocean and from the atmosphere into the ocean, respectively in that order. In this system, to avoid the above overestimation, an empirical technique to smooth out the extreme peak was adopted. Thus the coordinates for the refracted radiation was additionally considered. This procedure is tiresome, and yet the size of the system could not be reduced very much.

In this paper, therefore, computational accuracy of radiation reflected and refracted by the Cox-Munk model surface (1955) is discussed using the energy conservation of the incident radiation onto the surface. This model surface is simulated by many facets whose 
slopes are changed according to the Gaussian distribution with respect to wind speed. A numerical example is carried out at wavelength $0.5 \mu \mathrm{m}$ which is within the most transparent water region. To improve accuracy, the shadowing effect of the incident radiation onto the surfaces is also discussed. This effect becomes significant at a solar zenith angle of $\sim 90^{\circ}$. Furthermore, the effect of the multiple reflections and refractions by the model ocean surface are discussed. Finally, a computational example of albedo, the upwelling radiance and the degree of linear polarization at the top of the atmosphere are shown with respect to the effect of the ocean surface, the atmospheric and the oceanic constituents.

\section{Model Atmosphere-Ocean System}

Fig. 1 shows the diagram of the atmosphere-ocean system used in the present computations. The vertical concentration profile and size distribution of aerosols are given by Selby and McClatchey (1972). Visibil-

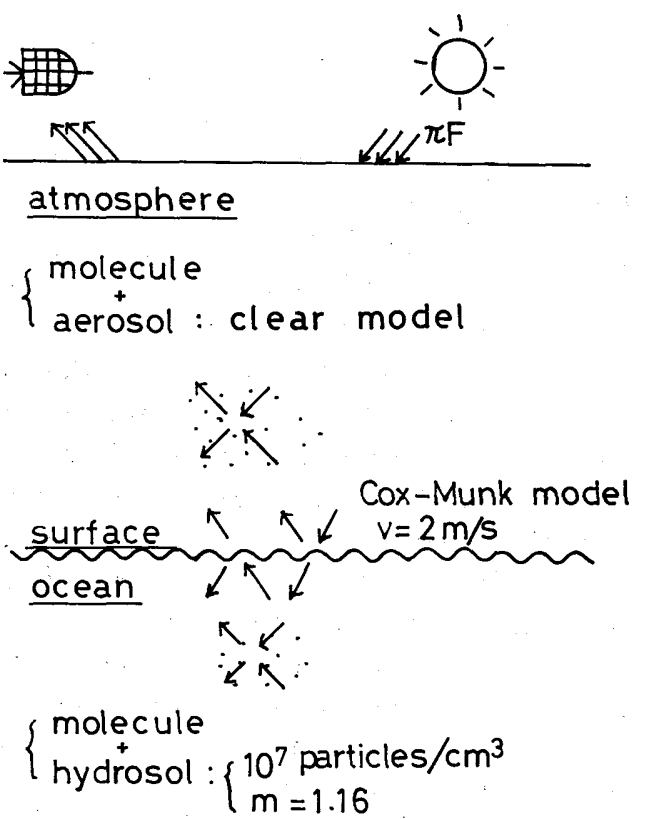

Fig. 1. Diagram showing the atmosphere-ocean system. ity of the atmosphere is in the clear model. The aerosols are assumed to be spherical, and their size distribution function is the same at all altitudes, given by the form:

$$
n(r)=\left\{\begin{array}{cl}
c \times 10^{4} & \text { for } 0.02 \mu \mathrm{m} \leq r \leq 0.1 \mu \mathrm{m} \\
c \times r^{-4} & \text { for } 0.1 \mu \mathrm{m} \leq r \leq 10.0 \mu \mathrm{m} \\
0 & \text { for } r \leq 0.02 \mu \mathrm{m} \text { or } \\
& r \geq 10.0 \mu \mathrm{m}
\end{array}\right.
$$

where the constant $c$ is normalized to 0.08824 for the case of 100 particles. The scattering phase matrix is computed at wavelength $0.5 \mu \mathrm{m}$ based on the refractive index of water $(m=$ 1.335-i0.0) given by Hale and Querry (1973). The optical thicknesses of atmospheric constituents such as aerosols $\left(\tau_{a}\right)$, molecules $\left(\tau_{r}\right)$ and ozone $\left(\tau_{o}\right)$ are given by $\tau_{a}=0.194, \tau_{r}=0.146$ and $\tau_{o}=0.00931$. The values of $\tau_{r}$ and $\tau_{o}$ are compiled for the summer mid-latitude region of the LOWTRAN 5 model atmosphere (Kneizys et al., 1980). Upon computing the emergent radiation, the inhomogeneous atmosphere is simulated by nine homogeneous sub-layers. The ocean surface is simulated by many facets whose slopes show an isotropic Gaussian distribution (Cox and Munk, 1955). The case of wind speed $2 \mathrm{~m} / \mathrm{sec}$ is considered. The ocean is assumed to be homogeneous and its bottom to absorb all radiation incident on it.

A pure water model is assumed for the molecular scattering and absorption. The scattering coefficient of pure water is given by Morel(1974), where the effect of the dissolved salts is ignored. This effect is usually neglected and can be of importance only for the clearest water. The absorption coefficients are obtained from the imaginary part of the refractive index of water given by Hale and Querry (1973). Little information is available for hydrosols, therefore in the present work, the data compiled by Tanaka and Nakajima (1977) is adopted, where the size distribution of hydrosols is given by the form :

$$
n(r)=\left\{\begin{array}{cl}
c_{s} \times r^{-4} & \text { for } 0.1 \mu \mathrm{m} \leq r \leq 22 \mu \mathrm{m} \\
0 & \text { for } r \leq 0.1 \mu \mathrm{m} \text { or } r \geq 22 \mu \mathrm{m}
\end{array}\right.
$$

where $n(r) \mathrm{d} r$ is the number density of hydrosols with radii between $r$ and $r+\mathrm{d} r$ and $c_{s}$ is a constant representing the turbidity condition. In this paper $c_{s}=30000$ is adopted, which 
corresponds to the hydrosol's number density of $10^{7}$ particles $/ \mathrm{cm}^{3}$. For the complex index of refraction of hydrosols, $m=1.16-i 0.0$ is adopted.

The incident radiation just beneath the ocean surface is attenuated $99.3 \%$ to become only $0.7 \%$ of the initial energy when it travels through ocean water of an optical thickness of 5. Therefore, the contribution of radiation below this depth is neglected. This assumption is equivalent to the condition that the ocean water is bounded by a black body at the depth of this optical thickness.

\section{Method of Calculation}

The doubling-adding method is used for calculations reported in this paper. Theoretical exposition and applications of the theory to an inhomogeneous atmosphere-ocean system have previously been presented by Takashima (1985). On computing the radiation, it is necessary to determine a set of discrete directions (quadrature points) appropriate to the atmosphere-ocean system. Fig. 2 shows a schematic diagram of the set of quadrature points. The region in the atmosphere is covered by $n_{1}$ quadrature points determined as zeros $\left(\mu_{i}^{a}\right)$ of the shifted $n_{1}$-th Legendre polynomial of range $(0,1)$, where $\mu_{i}^{a}$ are the cosines of the incident angles. The integral between the limits 0 and 1 is expressed by the LegendreGauss quadrature formula:

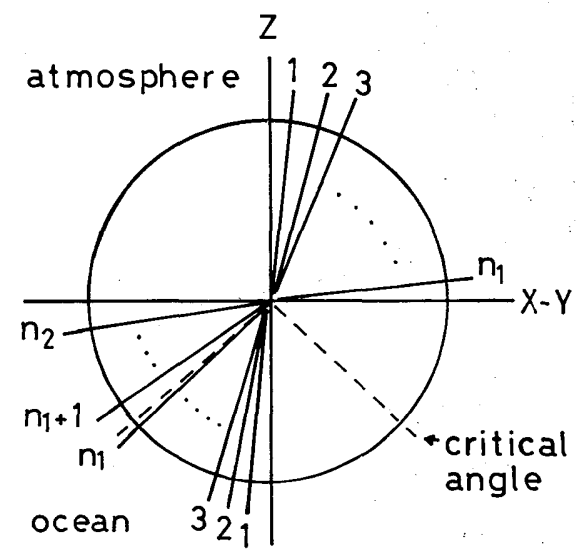

Fig. 2. Schematic diagram of the set of quadrature points.

$$
\int_{0}^{1} f\left(\mu^{a}\right) d \mu^{a}=\sum_{i=1}^{n 1} w_{i}^{a} f\left(\mu_{i}^{a}\right)
$$

where $w_{i}^{a}$ are the weights corresponding to $\mu_{i}^{a}$. The quadrature points $\left(\mu_{i}^{o}\right)$ within the ocean are found by Snell's law, namely

$$
\mu_{i}^{o}=\left(1-\left(1-\mu_{i}^{a 2}\right) / n^{2}\right)^{1 / 2}
$$

where $\mu_{i}^{o}$ are the cosines of the refracted angles within the ocean and $n$ is the index of refraction of water relative to air. The corresponding weights are

$$
w_{i}^{o}=w_{i}^{a} \mu_{i}^{a} /\left(\mu_{i}^{o} n^{2}\right)
$$

An additional set of $\left(n_{2}-n_{1}\right)$ quadrature points is mapped into the region from the critical angle to the horizon. They are determined as zeros of the shifted $\left(n_{2}-n_{1}\right)$-th Legendre polynomial of range $\left(0,\left(1-n^{-2}\right)^{1 / 2}\right)$.

\section{Reflection and Refraction Matrices Ex- pressed by the Cox-Munk Model.}

Cox and Munk made measurements of the sun glitter from aerial photographs (1954a,b). Their measurements covered wind speeds ranging from 0 to $14 \mathrm{~m} \mathrm{sec}^{-1}$. They found that there are thousands of dancing highlights in the photographs. At each highlight there must be a small water facet which is so inclined as to reflect an incoming ray from the sun towards the observer. To study these surface characteristics, let us consider the average brightness of the sea surface over a sufficiently long time and a sufficiently wide surface area to smooth out fluctuations due to individual glitter sparkles of sunglint. The average is then essentially independent of time but varies smoothly with the azimuth and the elevation of the sea surface under consideration. With this consideration, the ocean surface can be treated as a homogeneous air-water interface. Hence the surface can be numerically simulated by many facets, whose slope components show the Gaussian distribution with respect to surface wind (Cox and Munk, 1955). It is isotropic in the case of distribution independent of wind direction, but anisotropic in the case of distribution depending upon wind direction. It should be noted that with the increase of wind speed, the probability of white cap occurrence, which is the formation of innumerable bubbles, in- 
creases in the field of view. At present the optical properties of the white cap is not well known. Therefore in the present work, the effect of the white cap on the reflection and the refraction matrices of radiation is not yet undertaken. The density function of the wave slope $p\left(z_{\mathrm{x}}, z_{\mathrm{y}}\right)$ obeying an isotropic Gaussian distribution is expressed as

$$
p\left(z_{\mathrm{x}}, z_{\mathrm{y}}\right)=\left(\pi \sigma^{2}\right)^{-1} \exp \left(-\left(z_{\mathrm{x}}^{2}+z_{\mathrm{y}}^{2}\right) / \sigma^{2}\right)
$$

where $z_{\mathrm{x}}$ and $z_{\mathrm{y}}$ represent the slope components in the $X$ - and $Y$-directions in the sun vertical and the plane perpendicular to it, respectively. These are measured from the averaged smooth ocean surface. Cox and Munk (1955) found from airplane photographs that the mean square slope of $\sigma^{2}=\left\langle z_{\mathrm{x}}^{2}+z_{\mathrm{y}}^{2}\right\rangle_{\mathrm{Av}}$ increases, regardless of the direction, with the masthead wind speed of $v(\mathrm{~m} / \mathrm{sec})$ according to

$$
\sigma^{2}=0.003+0.00512 \times v \pm 0.004
$$

The reflection and the refraction matrices can be converted to parameters regarding to the incident and the reflected or refracted directions with the aid of spherical trigonometry. The reflection matrix is expressed by the form (Takashima, 1985) :

$$
\begin{aligned}
& \bar{R}_{s}\left(\mu_{1}, \mu_{0}, \phi_{1}-\phi_{0}\right) \\
& =\frac{4 a^{2}}{\sigma^{2}} \exp \left(\frac{1-2 a}{\sigma^{2}}\right) \bar{R}_{c}\left(\pi-\beta^{\prime}\right) \\
& \times \bar{R}_{s p}\left(\chi_{i}, \chi_{t}, n\right) \bar{R}_{c}\left(-\alpha^{\prime}\right)
\end{aligned}
$$

where parameter $a$ is given by

$$
a=\frac{1+\mu_{0} \mu_{1}-\sqrt{1-\mu_{0}^{2}} \sqrt{1-\mu_{1}^{2}} \cos \left(\phi_{1}-\phi_{0}\right)}{\left(\mu_{0}+\mu_{1}\right)^{2}}
$$

where $\phi_{0}$ and $\phi_{1}$ are the azimuth angles, $\mu_{0}$ and $\mu_{1}$ are cosines of incident and reflected directions in the meridian coordinates, respectively (Fig. 3). $\bar{R}_{s p}\left(\chi_{i}, \chi_{t}, n\right)$ is the reflection matrix of a specular surface expressed in Chandrasekhar's representation of the Stokes vector (Chandrasekhar, 1950) :

$$
\bar{R}_{s p}=\left(\begin{array}{lllll}
r^{2} & & & \\
& r_{\perp}^{2} & & & \\
& & -r_{\|} r_{\perp} & \\
& & & & -r_{\| \prime} r_{\perp}
\end{array}\right)
$$

where elements $r$ " and $r_{\perp}$ are given by Born and Wolf (1964) in the forms :

$$
\begin{aligned}
& r_{\text {" }}=-\frac{n \cos \chi_{i}-\cos x_{t}}{n \cos \chi_{i}+\cos \chi_{t}} \\
& r_{\perp}=\frac{\cos \chi_{i}-n \cos \chi_{t}}{\cos \chi_{i}+n \cos \chi_{t}}
\end{aligned}
$$

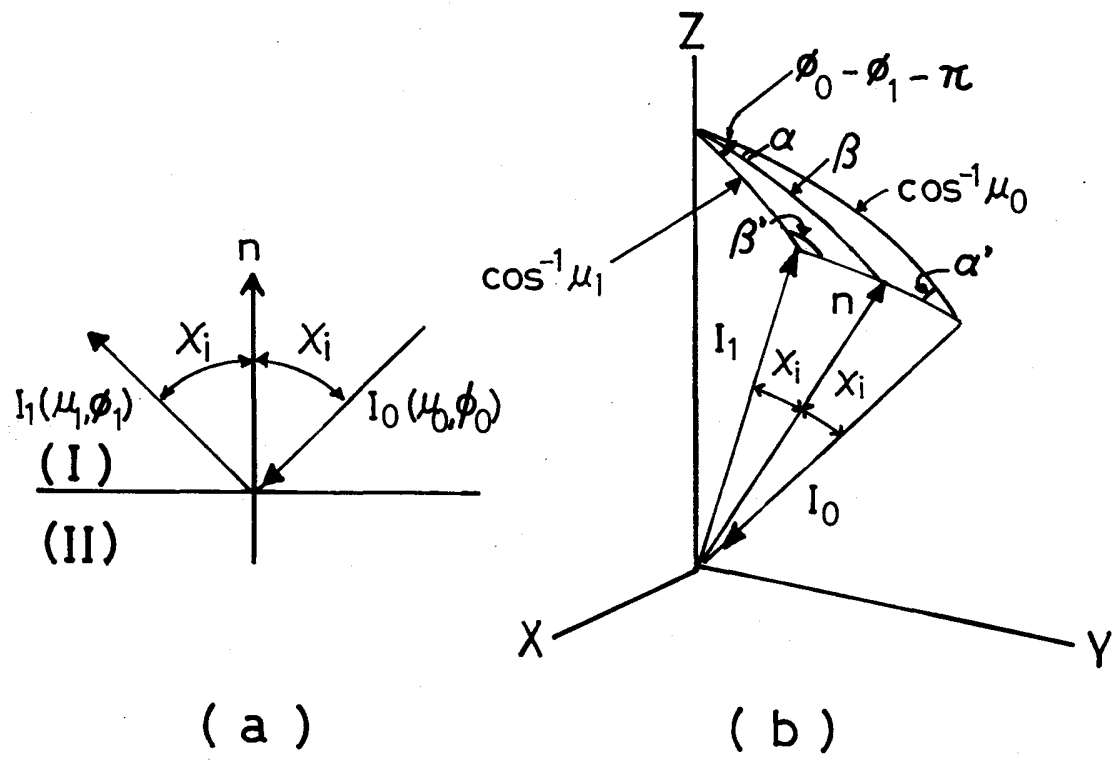

Fig. 3. Diagram showing the reflection by the ocean surface. $I_{0}$ and $I_{1}$ are the incident and the reflected radiation, respectively. $\mathbf{n}$ is the normal to the facet. $\phi_{0}$ and $\phi_{1}$ are the azimuth angles, $\mu_{0}$ and $\mu_{1}$ are cosines of the incident and the reflected direction in the meridian coordinates, respectively. $\chi_{i}$ is the incident or reflection angle to the facet. $\alpha$ and $\beta$ are the azimuth angle and tilt of the facet, respectively. $\quad \alpha^{\prime}$ and $\beta^{\prime}$ are rotation angles. 
where $\chi_{i}$ and $\chi_{t}$ are the incident and the refracted angle, respectively, and $n$ is the index of refraction of medium (II) relative to that of medium (I). $\bar{R}_{c}$ is the rotation matrix which is given by Chandrasekhar (1950) in the form :

$$
\bar{R}_{c}(\phi)=\left(\begin{array}{cc}
(1+\cos 2 \phi) / 2 & (1-\cos 2 \phi) / 2 \\
(1-\cos 2 \phi) / 2 & (1+\cos 2 \phi) / 2 \\
-\sin 2 \phi & \sin 2 \phi \\
0 & 0 \\
\sin 2 \phi / 2 & 0 \\
-\sin 2 \phi / 2 & 0 \\
\cos 2 \phi & 0 \\
0 & 1
\end{array}\right)
$$

In the scalar form, $\bar{R}_{s p}$ becomes $\left(r_{\|}{ }^{2}+r_{\perp}{ }^{2}\right) / 2$, and the rotation matrices are omitted. Similarly, the refraction matrix is expressed as

$$
\begin{aligned}
& \overline{R_{T}}\left(\mu_{2}, \mu_{0}, \phi_{2}-\phi_{0}\right)= \\
& \frac{4}{\sigma^{2}}\left(\frac{d-1 / n}{c}\right) \exp \left(\frac{1-\left(1+1 / n^{2}-2 d / n\right) / c^{2}}{\sigma^{2}}\right) \\
& \times\left(\frac{b}{c}\right) \bar{R}_{c}\left(\pi-\beta^{\prime}\right) \bar{T}_{s p}\left(\chi_{i}, \chi_{t}, n\right) \bar{R}_{c}\left(-\alpha^{\prime}\right)
\end{aligned}
$$

where

$$
\begin{aligned}
b & =\left(1-\mu_{0} \mu_{2} / n-(1 / n) \sqrt{1-\mu_{0}^{2}}\right. \\
& \left.\times \sqrt{1-\mu_{2}^{2}} \cos \left(\phi_{2}-\phi_{0}\right)\right) / c^{2} \\
c & =\mu_{2}-\mu_{0} / n
\end{aligned}
$$

$$
d=\mu_{0} \mu_{2}+\sqrt{1-\mu_{0}^{2}} \sqrt{1-\mu_{2}^{2}} \cos \left(\phi_{2}-\phi_{0}\right) \quad(17)
$$

Where $\phi_{0}$ and $\phi_{2}$ are the azimuth angles, $\mu_{0}$ and $\mu_{2}$ are cosines of incident and refracted directions in the meridian coordinates, respectively (Fig.4). $\bar{T}_{s p}\left(\chi_{i}, \chi_{t}, n\right)$ is the refraction matrix of the specular surface in the form:

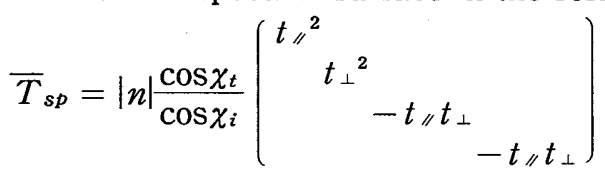

where elements $t_{\text {" }}$ and $t_{\perp}$ denote

$$
t^{\prime \prime}=\frac{2 \cos \chi_{i}}{n \cos \chi_{i}+\cos \chi_{t}}
$$

and

$$
t_{\perp}=\frac{2 \cos \chi_{i}}{\cos \chi_{i}+n \cos \chi_{t}}
$$

In the scalar form, $\bar{T}$ sp becomes $|n|$ $\left(\cos \chi_{t} / \cos \chi_{i}\right)\left(t_{\prime \prime}{ }^{2}+t_{\perp}{ }^{2}\right) / 2$, and the rotation matrices are omitted. The orientation of a facet is given as a function of $\left(\mu_{0}, \mu_{1}, \phi_{1}-\phi_{0}\right)$ or $\left(\mu_{0}\right.$, $\left.\mu_{2}, \phi_{2}-\phi_{0}, n\right)$. The effective area must be calculated when the relation between the direction of the incident radiation and the orientation of the facet is in the case of Fig. 5(b). The ratio of the effective area to the total area of the facet is given by (see Appendix):

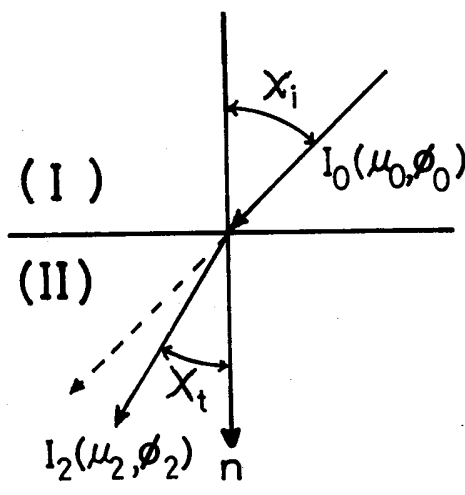

(a)

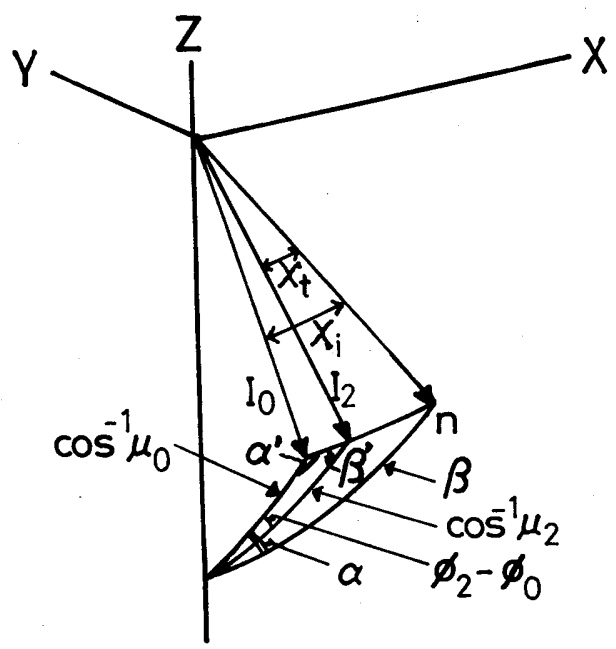

(b)

Fig. 4. Diagram showing the refraction by the ocean surface. $I_{0}$ and $I_{2}$ are the incident and the refracted radiation, respectively. $\chi_{i}$ and $\chi_{t}$ are the incident and the refraction angle to the facet, respectively. $\mathbf{n}, \phi_{0}, \mu_{0}, \phi_{2}, \mu_{2}, \alpha, \beta, \alpha^{\prime}$ and $\beta^{\prime}$ are similar to those of Fig. 3 . 


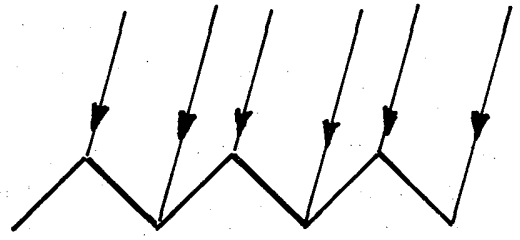

(a)

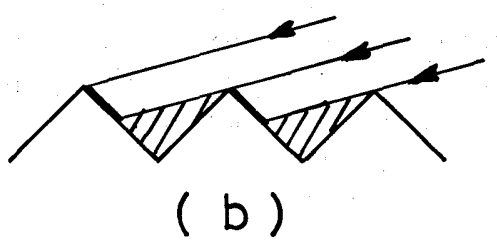

Fig. 5. Relation between the direction of the incident radiation and the orientation of the facet.

$r=2 \mu_{0} \cos \beta / \cos \chi_{i}$

(21)

Therefore $\bar{R}_{s}$ and $\bar{R}_{T}$ should be corrected by a factor of $r$. It should be noted that the reflectance $\rho_{j}$ and the transmittance $t_{j}$ can be related to

$$
\rho_{j}+t_{j}=1
$$

in agreement with law of conservation of energy. $\rho_{j}$ and $t_{j}$ in eq (22) are expressed by

$$
\begin{aligned}
\rho_{j}= & \frac{2 \pi}{\mu_{0 j}} \int_{0}^{1} \frac{1}{4 \pi \mu_{1}}\left\{\frac { 1 } { 2 \pi } \int _ { 0 } ^ { 2 \pi } \overline { R } _ { s } \left(\mu_{1}, \mu_{0 j}, \phi_{1}\right.\right. \\
& \left.\left.-\phi_{0 j}\right) d\left(\phi_{1}-\phi_{0 j}\right)\right\} \mu_{1} d \mu_{1} \\
t_{j}= & \frac{2 \pi}{\mu_{0 j}} \int_{0}^{1} \frac{1}{4 \pi \mu_{2}}\left\{\frac { 1 } { 2 \pi } \int _ { 0 } ^ { 2 \pi } \overline { R } _ { T } \left(\mu_{2}, \mu_{0 j}, \phi_{2}\right.\right. \\
& \left.\left.-\phi_{0 j}\right) d\left(\phi_{2}-\phi_{0 j}\right)\right\} \mu_{2} d \mu_{2}
\end{aligned}
$$

Equations (23) and (24) are expressed in the discrete coordinate system described in Chap. 3 as

$$
\begin{aligned}
\rho_{j} & =\frac{1}{2 \mu_{0 j}} \sum_{i=1}^{n 1} w_{i} \tilde{R}_{s}\left(\mu_{1 i}, \mu_{0 j}\right) \\
t_{j} & =\frac{1}{2 \mu_{0 j}} \sum_{i=1}^{n 2} w_{i} \tilde{R}_{T}\left(\mu_{2 i}, \mu_{0 j}\right)
\end{aligned}
$$

where $w_{i}$ are the weight functions of the Legendre-Gauss quadrature formula, and $\tilde{R}_{s}$ and $\tilde{R}_{T}$ are azimuth averaged radiance, which are expressed as

$$
\begin{array}{r}
\widetilde{R}_{s}\left(\mu_{1 i}, \mu_{0 j}\right)=\frac{1}{2 \pi} \int_{0}^{2 \pi} \bar{R}_{s}\left(\mu_{1 i}, \mu_{0 j},\right. \\
=\frac{1}{2 \pi} \sum_{k=1}^{n 3} w_{1 i} \bar{w}_{k} \bar{R}_{s j}\left(\mu_{1 i}, \mu_{0 j},\left(\phi_{1 i}-\phi_{0 j}\right)_{k}\right) \\
\tilde{R}_{T}\left(\mu_{2 i}, \mu_{0 j}\right)=\frac{1}{2 \pi} \int_{0}^{2 \pi} \bar{R}_{T}\left(\mu_{2 i}, \mu_{0 j},\right. \\
\left.\phi_{2 i}-\phi_{0 j}\right) d\left(\phi_{2 i}-\phi_{0 j}\right) \\
=\frac{1}{2 \pi} \sum_{k=1}^{n 3} w_{k} \bar{R}_{T}\left(\mu_{2 i}, \mu_{0 j},\left(\phi_{2 i}-\phi_{0 j}\right)_{k}\right)
\end{array}
$$

The Simpson rule was adopted for the integrations in eqs. (27) and (28).Eqs. (25) and (26) are for cases where the radiation is transmitted from the atmosphere to the ocean; when the transmission is reverse, $n_{1}$ and $n_{2}$ are exchanged.

\section{Computational Results and Discussions.}

Fig. 6 shows the reflectance $\rho$, the transmittance $t$, and their sum $\rho+t$ computed by eqs. (21), (25), (26), (27) and (28). $n_{1}$ and $n_{2}$ are numbers of quadrature points in the atmosphere and in the ocean, respectively. Fig. 7 shows the azimuth averaged radiances of the reflected radiation $\left(\widetilde{R}_{\mathrm{S}}\left(\mu_{1}, \mu_{0 j}\right) / 4 \pi \mu_{1}\right)$ and those of the refracted radiation $\left(\widetilde{R}_{T}\left(\mu_{2}, \mu_{0 j}\right) / 4 \pi \mu_{2}\right)$, respectively. In the case of $\left(n_{1}, n_{2}\right)=(100,140)$ in Fig. 6, the sum $\rho+t$ in eq. (22) becomes 1 , which is mostly satisfied, whereas in the cases of $\left(n_{1}, n_{2}\right)=(15,24)$ or $(30,45)$, the sum becomes $\rho+t>1$, when $\theta_{0}$ is small. This results mainly from the overestimation of the transmittance $t$. These facts are explained by using Fig. 7 as follows. The azimuth averaged radiances of the reflected radiation are relatively smooth, whereas those of the refracted radiation have sharp peaks at the directions connected by Snell's law ; therefore, the degree of the Legendre-Gauss quadrature formula of eq. (26) is too small to simulate the integration of eq. (24). In order to overcome this insufficiency, $n_{1}$ and $n_{2}$ should be fairly large. However, the computations with large values of $n_{1}$ and $n_{2}$, such as $(100,140)$, require a great deal of computer time and memory space, especially when the polarization effects are consid- 
(a)

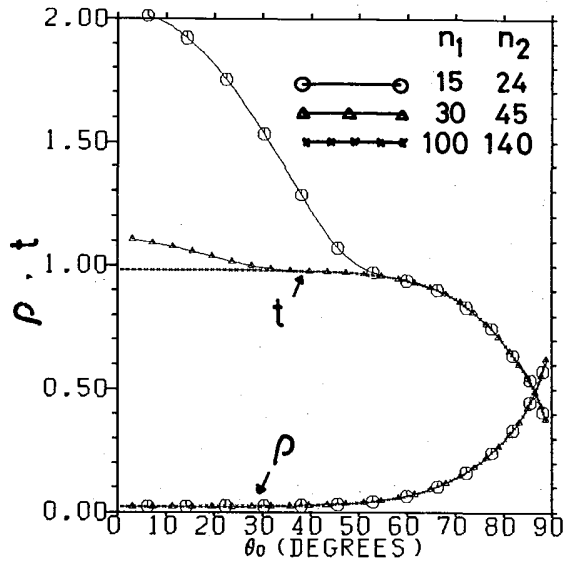

(c)

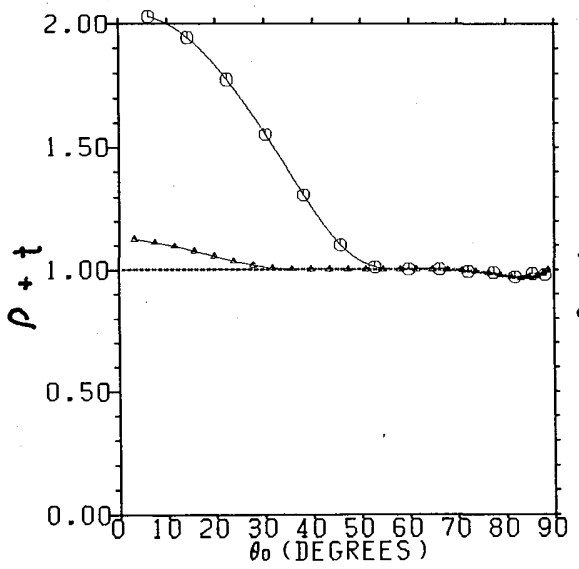

(b)

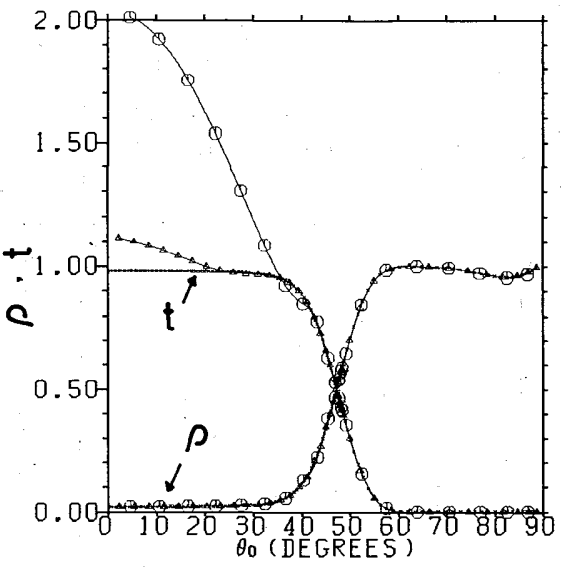

(d)

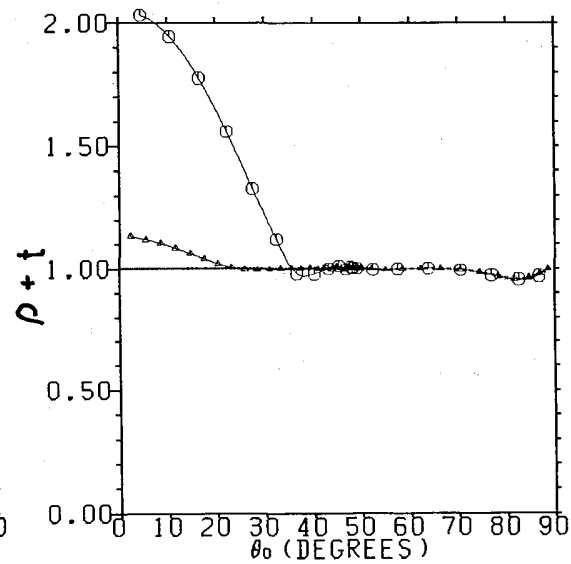

Fig. 6. Reflectance $\rho$, transmittance $t$ and their $\operatorname{sum} \rho+t$. (a) and (c) indicate the case where the incident radiation is from above the ocean surface, whereas (b) and (d) are from below it. $\theta_{0}$ in abscissae denotes the incident angle. $\quad n=1.335$ at $\lambda=0.5 \mu \mathrm{m}$ and $v=2 \mathrm{~m} /$ sec.

ered. Therefore, we modified the refraction matrix to be so efficient in computation that the condition $\rho_{j}+t_{j}=1$ might be satisfied:

$$
\begin{aligned}
1= & \rho_{j}+t_{j}=\frac{1}{2 \mu_{0 j}} \sum_{i=1}^{n 1} w_{i} \widetilde{R}_{s}\left(\mu_{1 i}, \mu_{0 j}\right) \\
& +\frac{1}{2 \mu_{0 j}} \sum_{\substack{i=1 \\
i \neq j}}^{n 2} w_{i} \widetilde{R}_{T}\left(\mu_{2 i}, \mu_{0 j}\right) \\
& +\frac{1}{2 \mu_{0 j}} w_{j} \widetilde{R}_{T}^{*}\left(\mu_{2 j}, \mu_{0 j}\right)
\end{aligned}
$$

where $\tilde{R}_{\mathrm{S}}$ and $\tilde{R}_{T}$ are computed by eqs. (27) and (28), respectively, whereas $\tilde{R}_{T}^{*}$ is given by

$$
\begin{aligned}
\widetilde{R}_{T}^{*}\left(\mu_{2 j}, \mu_{o j}\right)= & \left\{2 \mu_{0 j}-\sum_{i=1}^{n 1} w_{i} \widetilde{R}_{S}\left(\mu_{1 i}, \mu_{0 j}\right)\right. \\
& \left.-\sum_{\substack{i=1 \\
i \neq j}}^{n 2} w_{i} \widetilde{R}_{T}\left(\mu_{2 i}, \mu_{0 j}\right)\right\} / w_{j}
\end{aligned}
$$

To examine the usefulness of this modification in the atmosphere-ocean system, we computed the albedo and the azimuth averaged radiance of the upwelling radiation at the top with a modified system $(15,24)$ and a non-modified system $(100,140)$ (Fig. 8). To evaluate the radiance and the degree of polarization, the equation of radiative transfer is 
( a )

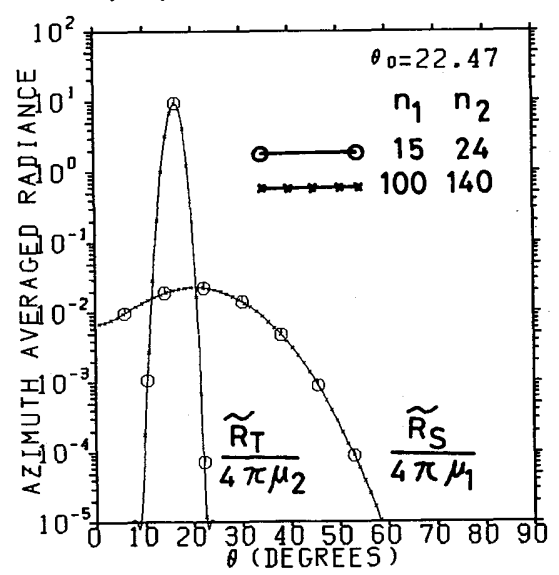

(b)

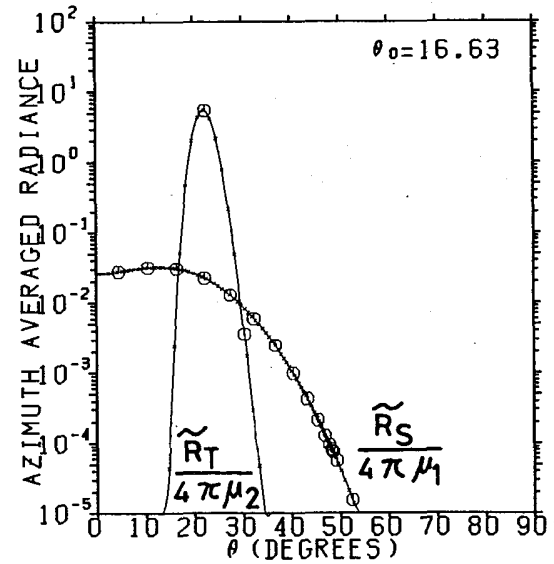

Fig. 7. Azimuth averaged radiance $(\pi \mathrm{F}=1)$.

Fig. 7a indicates the case where the incident radiation is transmitted from the atmosphere into the ocean, whereas in Fig. $7 \mathrm{~b}$ the transmission is reverse. The symbols $\theta_{0}$ and $\theta$ represent the incident and the reflection or refraction angle, respectively. $n=1.335$ at $\lambda=0.5 \mu \mathrm{m} . \quad v=2 \mathrm{~m} / \mathrm{sec}$.

\section{(a)}

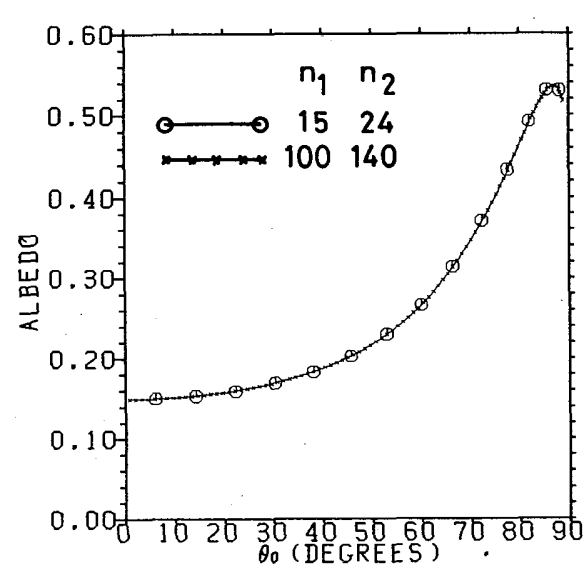

(b )

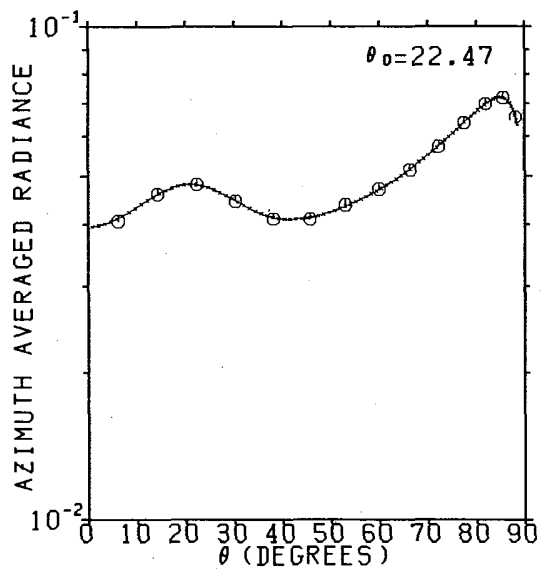

Fig. 8. (a) albedo and (b) azimuth averaged radiance at the top of the atmosphere $(\pi \mathrm{F}=1)$. The symbols $\theta_{0}$ and $\theta$ represent the solar zenith and the observation angles, respectively. $\lambda=0.5 \mu \mathrm{m}$ and $v=2 \mathrm{~m} / \mathrm{sec}$.

expanded into the Fourier series about an azimuthal difference. This computation would require a great deal of computer time and memory space. Therefore, we computed the albedo and the radiance averaged over the azimuth angle which corresponds to the first component of the Fourier series expansion in the scalar form. The values of both the albedo and the azimuth averaged radiance in the modified system $(15,24)$ agree with those in the system $(100,140)$. The detail results are also shown at Table 1 . This suggests that the method using eq. (30) is useful for the computation of the radiation in the atmosphere-ocean sys- 
Table 1. Relative differences (\%), between the values computed by the modified system $(15,24)$ and non-modified system $(100,140)$.

(a) albedo

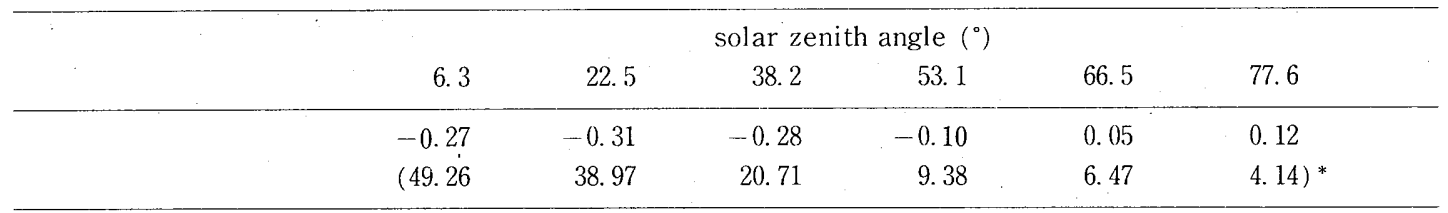

* As a reference, the relative differences (\%) between the two non-modified systems $(15,24)$ and $(100,140)$ are also shown.

(b) azimuth averaged radiance

\begin{tabular}{crrrrrr}
\hline $\begin{array}{c}\text { observation } \\
\text { angle }\left(^{\circ}\right)\end{array}$ & 6.3 & 22.5 & 38.2 & 53.1 & \multicolumn{1}{c}{ sol ar zenith angle $\left(^{\circ}\right)$} & 77.6 \\
\hline 6.3 & -0.75 & -1.58 & -1.84 & -1.56 & -1.15 & -0.72 \\
22.5 & -0.04 & 0.15 & -0.10 & 0.04 & 0.14 & 0.15 \\
38.2 & -0.94 & -0.89 & -0.63 & -0.61 & -0.41 & -0.18 \\
53.1 & 0.54 & 0.44 & 0.44 & 0.60 & 0.49 & 0.34 \\
66.5 & -0.39 & -0.51 & -0.45 & -0.18 & 0.13 & 0.16 \\
77.6 & -0.02 & -0.16 & -0.14 & -0.04 & 0.13 & 0.27 \\
\hline
\end{tabular}

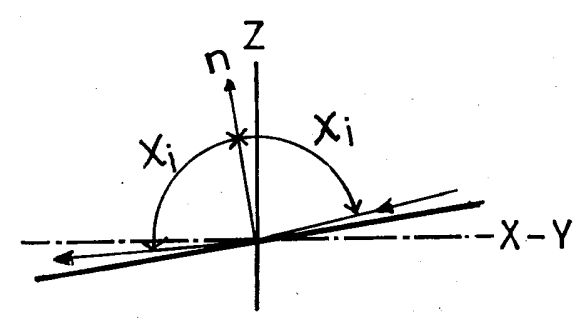

Fig. 9. Example of reflected radiation directed towards the opposite hemisphere.

tem even for rather small-size discrete coordinate systems.

It should be noted that there exist regions where the $\operatorname{sum} \rho+t<1$ when $\theta_{0}$ is between $70^{\circ}$ and $90^{\circ}$ in Fig. 6 . This may be partly due to the fact that the computation of radiations whose incident and reflected directions are in the opposite hemispheres to each other (Fig. 9) is not included in eqs. (23) or (25). Furthemore, multiple reflections and refractions, such as shown in Fig. 10, are not considered in the present computations. Fortunately, the effects of these errors are negligible for the computation of radiation in the entire atmosphere-ocean

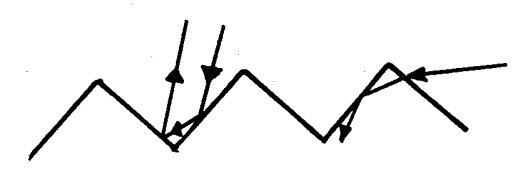

Fig. 10. Example of multiple reflections and refractions by the ocean surface.

system.

Finally, we show the albedo, the radiance and the degree of polarization at the top of the atmosphere-ocean system denoted by $(\mathrm{A}+\mathrm{S}+$ $\mathrm{O} ; \times)$, with a modified system $(15,24)$ (Fig. 11). To evaluate the effect of the ocean surface and the hydrosols in the ocean, the results for the atmosphere-surface system $(A+S: \Delta)$, where the radiation into the ocean is assumed to be completely absorbed and for the atmosphere only $(\mathrm{A} ; \mathrm{O})$ are also shown. Fig. 11a shows the albedo where $\theta_{0}$ is the solar zenith angles. Three figures of Fig. 11b show the radiance for the solar zenith angles $\left(\theta_{0}\right) 66.46^{\circ}$, 
$38.23^{\circ}$ and $6.28^{\circ}$ from top to bottom, respectively, where the abscissa denotes the nadir angle of observations $(\theta)$ with the solar horizon on the left $\left(\phi=0^{\circ}\right)$, nadir at the center, and the antisolar horizon on the right $\left(\phi=180^{\circ}\right)$. The corresponding degrees of polarization are shown in Fig. 11c. The values of the albedo and the radiance increase in the order of $\mathrm{A}, \mathrm{A}+$ $\mathrm{S}, \mathrm{A}+\mathrm{S}+\mathrm{O}$ by the effect of the ocean surface and the hydrosols in the ocean. Radiance is relatively high at large nadir angles of observations due to the atmospheric scattering, and strong sunglints are noted at the specular directions. The effect of the hydrosols is strong in the region of the small nadir angle of observations $(\theta)$, and decreases as $\theta$ approaches to the horizon or the sunglint region. As for the degree of polarization, one or two maximal values appear for large solar zenith angles ( 38 . $23^{\circ}$ and $66.46^{\circ}$ ). One is located in the direction $\sim 90^{\circ}$ away from the solar incident direction, mainly from the atmospheric scattering $\left(\mathrm{P}_{\max }^{90}\right)$. The other maximum degree of polarization $\left(\mathrm{P}_{\max } \mathrm{s}\right)$ appears near the specular direction in the case of $\mathrm{A}+\mathrm{S}$ and $\mathrm{A}+\mathrm{S}+\mathrm{O}$, resulting from the radiation reflected by the surface; $\mathrm{P}_{\max }{ }^{\mathrm{s}}$ appears when $\theta_{0}$ is near the Brewster angle (53. $3^{\circ}$ ), where the reflected radiation is most polarized. For $\theta_{0}=66.46^{\circ}, \mathrm{P}_{\max }{ }^{\mathrm{s}}$ appears separately from $\mathrm{P}_{\max }{ }^{90}$, whereas for $\theta_{0}=38.23^{\circ}, \mathrm{P}_{\max }{ }^{\text {s }}$ does not appear separately from $\mathrm{P}_{\max }{ }^{90}$. It should be noted that for $\theta_{0}=6.28^{\circ}, \mathrm{P}_{\max }$ s does not appear because of the small degree of polarization of radiation reflected by the surface. The degree of polarization decreases by the effect of hydrosols, because the upward radiation travelling diffusely through the air-ocean boundary disturbs the radiation field in the atmosphere.

\section{Conclusion}

Upon computing the radiation in the atmosphere-ocean system, large quadrature points such as $(100,140)$ in the discrete coordinates must be adopted to obtain sufficient accuracy in the numerical results, because the radiation refracted by the ocean surface should be simulated appropriately, which becomes very large with a sharp peak at the direction connected with the incident direction by Snell's law. Computation with such a large system, however, requires a great deal of computer time and memory space. To avoid this difficulty, we have presented the method of modification of the refraction matrix so that the law of energy conservation at the surface might be satisfied. Using the present method, satisfactory accuracy on computations has been obtained even in the case of rather small quadrature points in discrete coordinates such as $(15,24)$. This method makes it possible to compute the radiation in the entire atmosphere ocean system including the polarization effect with a moderate size computer. The effects of

\section{(a)}

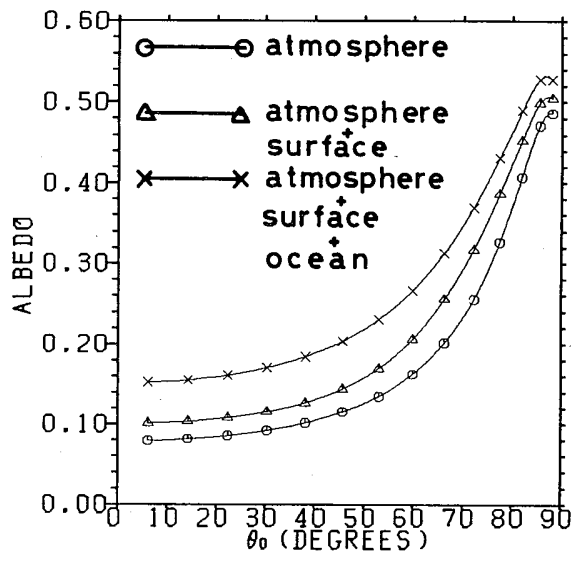

Fig. 11. (a) albedo, (b) radiance and (c) degree of linear polarization at the top of the atmosphere $(\pi \mathrm{F}=1)$. The symbols $\theta_{0}$ and $\theta$ represent the solar zenith and the observation angles, respectively. $\lambda=0.5 \mu \mathrm{m}$ and $v=2 \mathrm{~m} / \mathrm{sec} . \quad\left(n_{1}, \quad n_{2}\right)=(15,24)$. Principal plane is shown in Figs. (b) and (c). 
multiple reflections and refractions as well as that of the white cap which is formed by innumerable bubbles are not included in the present computation technique. In order to simulate the ocean surface more accurately, the
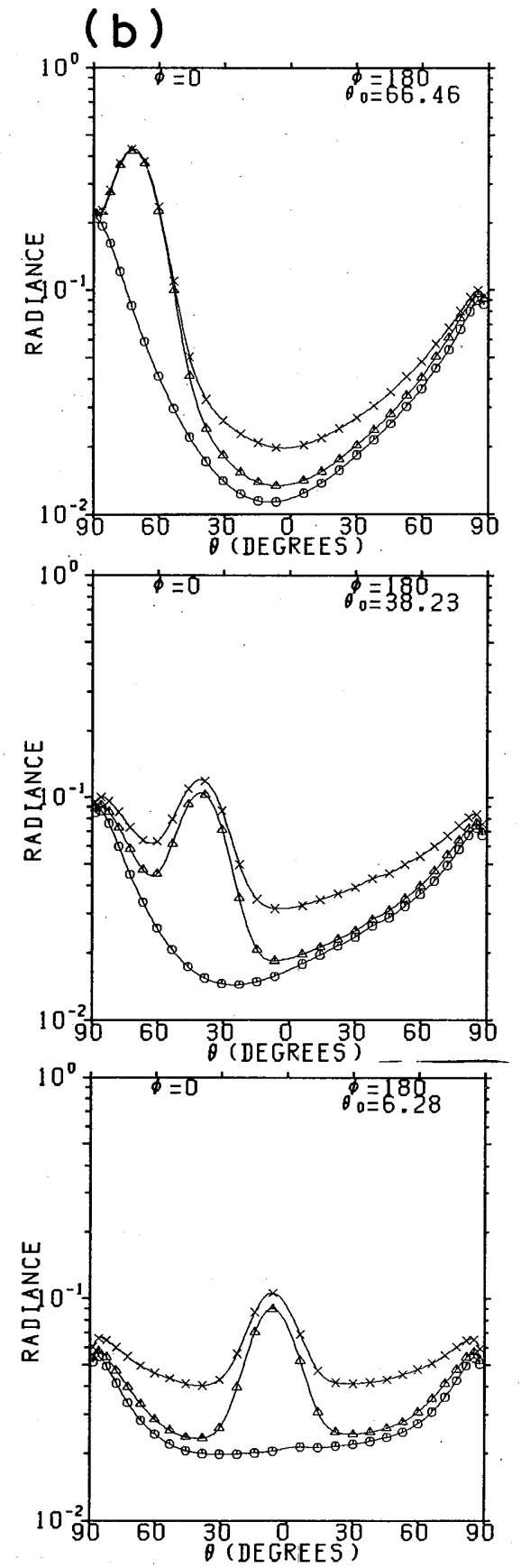

development of a technique to include these effects is desired for the reflection and refraction matrices of radiation.

Acknowledgements: The authors wish to
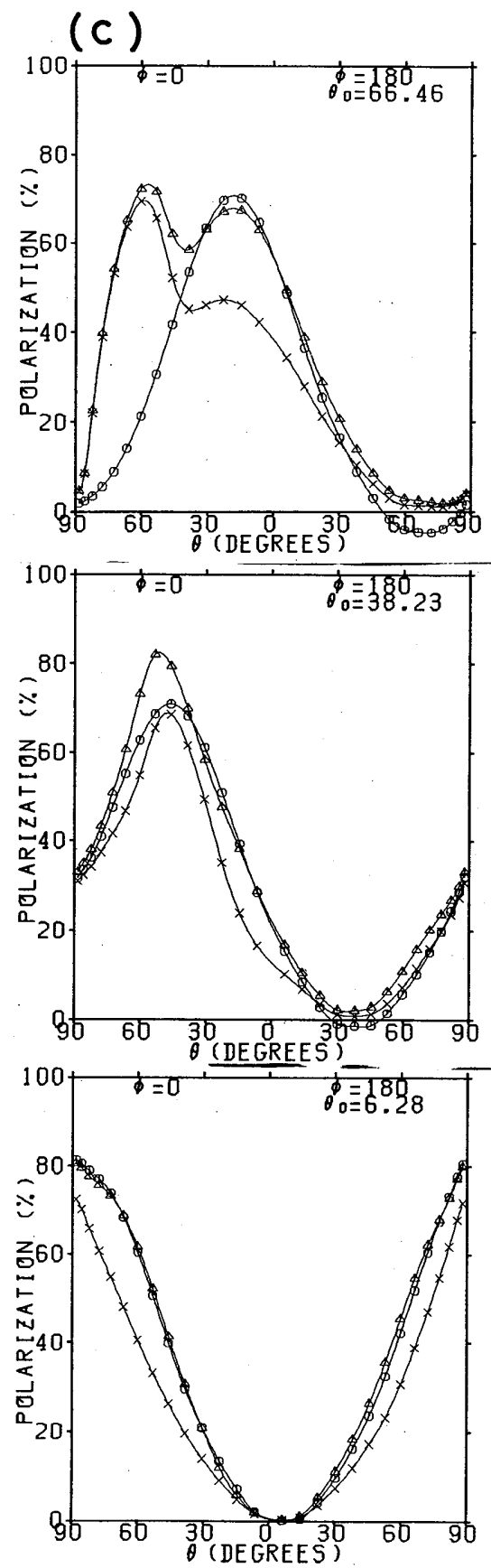

Fig. 11. continued 
express their thanks to Yohzo Takayama of the Meteorological Research Institute for his useful suggestions about computation. The computations were carried out by the HITAC $\mathrm{M} 200 \mathrm{H}$ of the MRI.

\section{APPENDIX. Effective Area of the Facet.}

In order to estimate the effect of the adjacent regions to the facet, we set the plane $\pi$ parallel to the facet and planes corresponding to the adjacent regions as shown in Figs. a and b. Without loss of generality, the incident direction of radiation $\mathrm{I}_{0}$ can be parallel to the $Z$ - $Y$ plane. The direction cosines of $\mathrm{I}_{0}$ are

$\left(a_{1}, b_{1} c_{1}\right)=\left(0,-\sin \theta_{0},-\cos \theta_{0}\right)$

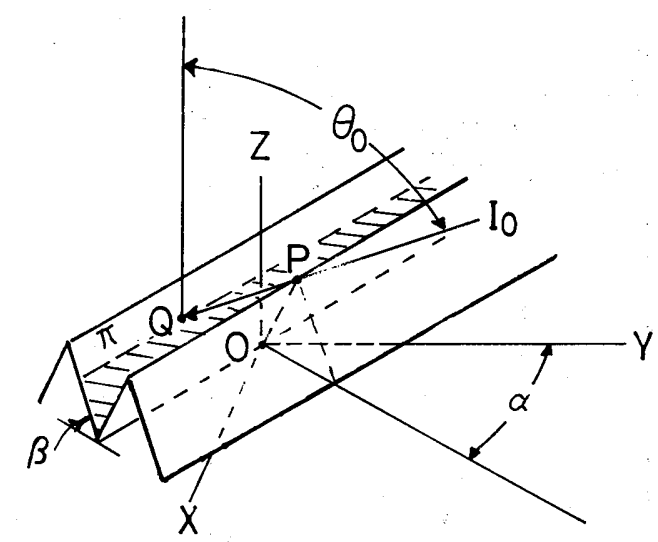

(a) .

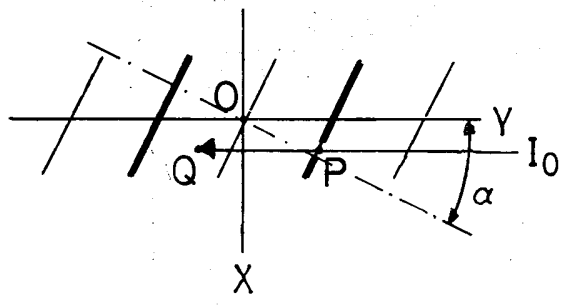

(b) where $\theta_{0}$ is the zenith angle of $I_{0}$. The direction cosines of the normal of plane $\pi$ are $\left(a_{0}, b_{0}, c_{0}\right)=(\sin \alpha \sin \beta, \operatorname{con} \alpha \sin \beta, \cos \beta)$

where $\alpha$ and $\beta$ are the azimuth angle and tilt of plane $\pi$. The coordinates of the point $\mathrm{P}$ are $\left(x_{1}, y_{1}, z_{1}\right)=(\sin \alpha \cot \beta, \cos \alpha \cot \beta, 1)$

assuming the height of the point $\mathrm{P}$ to be 1 . With the aid of elementary geometry, the equation of a plane is expressed as

$$
a_{0}\left(x-x_{0}\right)+b_{0}\left(y-y_{0}\right)+c_{0}\left(z-z_{0}\right)=0(\mathrm{a}-4)
$$

where $\left(a_{0}, b_{0}, c_{0}\right)$ are the direction cosines of the normal to the plane, and $\left(x_{0}, y_{0}, z_{0}\right)$ are the coordinates of a point on it. The equation of a straight line is expressed, by using parameter $t$, as

$$
\left\{\begin{array}{l}
x=x_{1}+t a_{1} \\
y=y_{1}+t b_{1} \\
z=z_{1}+t c_{1}
\end{array}\right.
$$

where $\left(a_{1}, b_{1}, c_{1}\right)$ are the direction cosines of the line and $\left(x_{1}, y_{1}, z_{1}\right)$ are the coordinates of a point on it. Substitution of eq. (a-5) into eq. (a-4) yields the parameter $t$ which gives the point of the intersection of the plane and the straight line :

$t=\frac{a_{0}\left(x_{0}-x_{1}\right)+b_{0}\left(y_{0}-y_{1}\right)+c_{0}\left(z_{0}-z_{1}\right)}{a_{0} a_{1}+b_{0} b_{1}+c_{0} c_{1}}$

Considering that the origin $\mathrm{O}\left(\left(x_{0}, \mathrm{y}_{0}, z_{0}\right)=\right.$ $(0,0,0))$ lies on the plane $\pi$, eqs. $(a-1),(a-2)$, $(\mathrm{a}-3)$ and $(\mathrm{a}-6)$ yield the parameter $t$ which gives the point $\mathrm{Q}$ of the intersection of the plane $\pi$ and the line $\mathrm{I}_{0}$,

$t=2 \cos \beta /\left(\cos \alpha \sin \beta \sin \theta_{0}+\cos \beta \cos \right.$ $\left.\theta_{0}\right)$.

The denominator can be transformed into $\cos \chi_{i}$ with the aid of Fig. 3b. Therefore, the $Z$-coordinate of the point $\mathrm{Q}$ is

$$
z_{Q}=1-2 \cos \theta_{0} \cos \beta / \cos \chi_{i}
$$
and

$$
r=1-z_{Q}=2 \cos \theta_{0} \cos \beta / \cos \chi_{i} .
$$

\section{References}

Born, M. and E. Wolf, 1964 : Principles of Optics, Pergamon, Oxford.

Chandrasekhar, S., 1950: Radiative Transfer, pp 393, Clarendon Press, Oxford. 
Cox, C. and W. Munk, 1954a: Statistics of the sea surface derived from sun glitter, J. Mar. Res., 13, 198-227.

Cox, C. and W. Munk, 1954b: Measurement of the roughness of the sea surface from photographs of the sun's glitter, J. Opt. Soc. Amer., 44, 838-850.

Cox, C. and W. Munk, 1955: Some problems in optical oceanography, J. Mar. Res., 14, 63-78.

Hale, G.M. and M.R. Querry, 1973 : Optical constants of water in the $200-\mathrm{nm}$ to $200-\mu \mathrm{m}$ wavelength region, Appl. Opt., 12, 555-563.

Kneizys, F.X. et al., 1980 : Atmospheric Transmittance/ Radiance Computer Code LOWTRAN 5, Air Force Geophy. Lab., AFGL-TR-80-0067.

Morel, A., 1974 : "Optical properties of pure water and pure sea water", in Optical Aspects of Oreanography, N.G. Jerlov and E.S. Nielsen, Eds., Academic
Press, London, Chap. 1.

Selby, J.E.A. and R.M. McClatchey, 1972 : Atmsopheric Transmittance from 0.25 to $28.5 \mu \mathrm{m}$ : Computer Code LOWTRAN 2, Air Force Cambridge Research Lab., AFCRL-72-0745.

Takashima, T., 1985: Polarization effect on radiative transfer in planetary composite atmospheres with interacting interface, Earth, Moon and Planets, 33, 59-97.

Tanaka, M. and T. Nakajima, 1977 : Effects of oceanic turbidity and index of refraction of hydrosols on the flux of solar radiation in the atmosphere-ocean system, J. Quant. Spectrosc. Radiat. Transfer, 18, 93-111.

\title{
大気一海洋系モデルにおける海面からの放射の計算精度
}

\author{
増田一彦・高島 勉
}

\begin{abstract}
可視から近赤外域の波長での放射伝達のシミュレーションを行う場合には, 海面での反射, 屈折の取り扱いが計算精度上 重要である。本論文では計算方法として doubling-adding 法を用いる場合の反射・風折 matrix を等方的 Cox-Munk 海面モ デルを用いて表し，その計算精度を海面でのエネルギ保存に注目して検証した。ただしこの海面モデルでは多重反射・多重 屈折の効果は無視してある。波長としては比較的海水の透明度の高い $0.5 \mu \mathrm{m}$ を用いた。検証方法としては大気中, 海水中 に扔りる quadrature point の数を様々に変化させて,それらの結果を比較する方法で行った。その結果属折 matrix に若干 の補正を加えると比較的 point 数の少い $(15,24)$ の場合にも満足する結果が得られた。このことは多大な計算時間と記憶 容量が必要な偏光度の計算を含むシミュレーションでは特に重要である。また太陽の天頂角が大きい場合に生ずる shadow の問題を解決する方法を示し, 多重反射, 多重屈折等による誤差についても若千の検討を行った。最後に大気上端でのアル ベド，上向き放射輝度・偏光度の計算結果の例を示した。
\end{abstract}

